\title{
ゾルゲル法によるムライトの生成に及ぼす遷移金属化合物の影響
}

門側 幸宏・山崎泰男

(関西大学工学部, 564 吹田市山手町 3-3-35)

\section{Effect of Transition Metal Compounds on the Formation of Mullite by the Sol-Gel Method}

\author{
Yukihiro KADOGAWA and Yasuo YAMASAKI \\ (Faculty of Engineering, Kansai University, 3-35, Yamate-cho 3-chome, Suita-shi, Osaka \\ 564)
}

Mullite was synthesized by a sol-gel method from the mixed solutions of $\mathrm{Si}\left(\mathrm{OC}_{2} \mathrm{H}_{5}\right)_{4}$ and $\mathrm{Al}\left(\mathrm{NO}_{3}\right)_{3}$ with small amounts of the mineralizing additives such as $\mathrm{MnCl}_{2}, \mathrm{Fe}\left(\mathrm{NO}_{3}\right)_{3}, \mathrm{CoCl}_{2}, \mathrm{Ni}\left(\mathrm{NO}_{3}\right)_{2}$ or $\mathrm{CuCl}_{2}$. The formation of mullite began at about $1100^{\circ} \mathrm{C}$ for the sample with $3.73 \times 10^{-3} \mathrm{~mol}\left(R_{\mathrm{Cu}}=3.74 \times 10^{-2}\right) \mathrm{CuCl}_{2} \cdot 2 \mathrm{H}_{2} \mathrm{O}$. The accelerating effect of mullite formation was observed for all samples with mineralizing additives except those with more than $3.64 \times 10^{-3} \mathrm{~mol}\left(R_{\text {Mn }}=\right.$ $\left.2.94 \times 10^{-2}\right) \mathrm{MnCl}_{2} \cdot 4 \mathrm{H}_{2} \mathrm{O}$ and, with less than $1.61 \times 10^{-3} \mathrm{~mol}\left(\mathrm{R}_{\mathrm{Fe}}=1.44 \times 10^{-2}\right) \mathrm{Fe}\left(\mathrm{NO}_{3}\right)_{3} \cdot 9 \mathrm{H}_{2} \mathrm{O}$ and $1.78 \times 10^{-3} \mathrm{~mol}$ $\left(R_{c o}=1.23 \times 10^{-2}\right) \mathrm{CoCl}_{2} \cdot 6 \mathrm{H}_{2} \mathrm{O} . \mathrm{Ni}\left(\mathrm{NO}_{3}\right)_{2}$ was most effective for the accelerating of mullite formation among the mineralizing additives.

[Received October 19, 1988; Accepted December 15, 1988]

Key-words : Synthesis, Mullite, Aluminium nitrate, Ethyl silicate, Transition metal compounds, Sol-gel method

\section{1. 緒 言}

ムライト $\left(3 \mathrm{Al}_{2} \mathrm{O}_{3} \cdot 2 \mathrm{SiO}_{2}\right)$ は, $\mathrm{Al}_{2} \mathrm{O}_{3}-\mathrm{SiO}_{2}$ 二成分系 の唯一の安定な化合物である1). ムライトセラミックス は, クリープ抵抗力が高く，また熱膨張係数が小さいな ぞ優れた特性をもっているので, 最近, 高温用構造材料 として注目されている21.

ムライトは, これまで, 硝酸アルミニウム水溶液とケ イ酸エチルを原料に用いて噴霧熱分解法 ${ }^{3)}$ (4)で, またア ルミニウムイソプロポキシドとケイ酸エチルを原料に用 (て噴霧熱分解法 ${ }^{5)}$, 加水分解法 ${ }^{6) ~ 8)}$, および水熱法 ${ }^{9), 10)}$ で合成されている。

著者らは, 原料に水溶液を用いるセラミックス粉体の 合成法を開発し，既に，二，三の複酸化物の合成につい て報告した ${ }^{11) ~ 13)}$. 本報では, 硝酸アルミニウム水溶液 とケイ酸エチルを原料に用い, 鉱化剂として遷移金属の 塩化物あるいは硝酸塩の水溶液をそれぞれ単独で加えた 混合溶液からゾルゲル法を利用してムライトを合成した ので，その結果について報告する.

\section{2. 実験方法}

シリカ $\left(\mathrm{SiO}_{2}\right)$ の原料には, ケイ酸エチル $\left(\mathrm{Si}\left(\mathrm{OC}_{2} \mathrm{H}_{5}\right)_{4}\right)$ を,また, アルミナ $\left(\mathrm{Al}_{2} \mathrm{O}_{3}\right)$ の原料には, 硝酸アルミ ニウム $\left(\mathrm{Al}\left(\mathrm{NO}_{3}\right)_{3} \cdot 9 \mathrm{H}_{2} \mathrm{O}\right)$ を用いた。鉱化剂としては, $\mathrm{MnCl}_{2} \cdot 4 \mathrm{H}_{2} \mathrm{O}, \quad \mathrm{Fe}\left(\mathrm{NO}_{3}\right)_{3} \cdot 9 \mathrm{H}_{2} \mathrm{O}, \quad \mathrm{CoCl}_{2} \cdot 6 \mathrm{H}_{2} \mathrm{O}, \quad \mathrm{Ni}$ $\left(\mathrm{NO}_{3}\right)_{2} \cdot 6 \mathrm{H}_{2} \mathrm{O}$ ，および $\mathrm{CuCl}_{2} \cdot 2 \mathrm{H}_{2} \mathrm{O}$ を用いた。

ゾル (均一溶液) の調製法の一例を示すと, つぎの通 りである.ムライト $\left(3 \mathrm{Al}_{2} \mathrm{O}_{3} \cdot 2 \mathrm{SiO}_{2}\right)$ 組成になるよう
に，ケイ酸エチル $\left(\mathrm{Si}\left(\mathrm{OC}_{2} \mathrm{H}_{5}\right)_{4}\right) 32.77 \mathrm{~g}(0.1573 \mathrm{~mol})$

と, 硝酸アルミニウム $\left(\mathrm{Al}\left(\mathrm{NO}_{3}\right)_{3} \cdot 9 \mathrm{H}_{2} \mathrm{O}\right) 177.07 \mathrm{~g}$ $(0.4720 \mathrm{~mol})$ を蒸留水 $100 \mathrm{ml}$ に溶かした水溶液との 不均一混合溶液に，鉱化剂として，たとえば， $\mathrm{Ni}$ $\left(\mathrm{NO}_{3}\right)_{2} \cdot 6 \mathrm{H}_{2} \mathrm{O} 29.08 \mathrm{~g}(0.1 \mathrm{~mol})$ を $100 \mathrm{ml}$ の蒸留水に 溶功した水溶液の $8 \times 10^{-3} \mathrm{~L}(\mathrm{Ni}-4)$ を加え，さらに塩酸 (ケイ酸エチル 1 モルに対して $0.06 \mathrm{~mol}$ ) を加えて, 室 温で 3 時間擋はん混合して反応させると, 透明で均一な 溶液（ゾル）が得られた．ほかの鉱化剤およびその添加 量の場合にも同様に行った。このような操作によって得 られた溶液をガラス製シャーレ $(150 \phi \mathrm{mm})$ に移して, 大気中に一昼夜放置しておくと，ゲル化したのでそのま ま自然乾燥させたのち, さらに $120^{\circ} \mathrm{C}$ で数日間乾燥さ せた．乾燥ゲル（以下，ゲルと略す）の少量を半融アル ミナるつぼに入れ, $1000^{\circ} \sim 1300^{\circ} \mathrm{C}$ の所定の温度で 30 分間熱処理を施して室温に冷却し, めのう乳鉢で粉砕し て X 線分析の試料とした. 粉末 X 線回折には, 理学電 機製ガイガーフレックス CN 2013 を使用した。測定条 件は, $\mathrm{Cu} K \alpha$ 線 $(\mathrm{Ni}$ フィルター), $30 \mathrm{kV}, 10 \mathrm{~mA}$, 時 定数 0.5 秒, 走查速度 $2 \% \mathrm{~min}$ である.

なお，鉱化剤の添加量は，原料溶液組成から生成する ムライト (Mullite) の量（計算上， $0.0787 \mathrm{~mol})$ との モル比， $R$ で表した。 たとえば, $\mathrm{Ni}\left(\mathrm{NO}_{3}\right)_{2}$ の添加量, $R_{\mathrm{Ni}}$ は, $\mathrm{Ni}\left(\mathrm{NO}_{3}\right)_{2} \cdot 6 \mathrm{H}_{2} \mathrm{O}$ の添加量 $(\mathrm{Ni}-4$ の場合には, $\left.7.01 \times 10^{-3} \mathrm{~mol}\right)$ から $\mathrm{Ni}\left(\mathrm{NO}_{3}\right)_{2}$ の添加量 $\left(4.41 \times 10^{-3}\right.$ $\mathrm{mol})$ を求め, これとムライトの量 $(0.0787 \mathrm{~mol})$ との 比 $\left(\mathrm{Ni}\left(\mathrm{NO}_{3}\right)_{2} / \mathrm{Mullite}=5.60 \times 10^{-2}\right)$ で表した.このほ 
かの鉱化剤およびその添加量についても同様に行った.

\section{3. 結果および考察}

硝酸アルミニウム水溶液とケイ酸エチルのみからゾル ゲル法で作製したゲルを $1000^{\circ} \sim 1300^{\circ} \mathrm{C}$ の所定の温度で 30 分間熱処理を施して得た試料 (No.1) のX.線回折の 結果を図 1 に示す. 無印は, 未確認の回折線である.ム ライト ${ }^{14), 15)}$ (○印) は, $1200^{\circ} \mathrm{C}$ 付近から生成し始め, 熱処理温度の上昇とともにその粒子成長は顕著になっ た。また， $1100^{\circ}$ および $1200^{\circ} \mathrm{C}$ で熱処理した場合には， ムライトの回折線（○印）のほかに，Al-Si スピネル9)

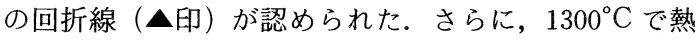
処理した場合には，ムライトの回折線のほかに， $\alpha$ $\mathrm{Al}_{2} \mathrm{O}_{3}{ }^{15)}\left(2 \theta=43.4^{\circ}(d=2.085 \AA)\right)$ の回折線 (○印) がわずかに認められた。したがって，ムライト単一相は 得られなかった。

つぎに，硝酸アルミニウム水溶液とケイ酸エチルに， $\mathrm{MnCl}_{2} \cdot 4 \mathrm{H}_{2} \mathrm{O} 5.46 \times 10^{-3} \mathrm{~mol}\left(R_{\mathrm{Mn}}=4.41 \times 10^{-2}\right), \quad \mathrm{Fe}$ $\left(\mathrm{NO}_{3}\right)_{3} \cdot 9 \mathrm{H}_{2} \mathrm{O} 1.61 \times 10^{-3} \mathrm{~mol}\left(R_{\mathrm{Fe}}=1.44 \times 10^{-2}\right)$, $\mathrm{CoCl}_{2} \cdot 6 \mathrm{H}_{2} \mathrm{O} 7.12 \times 10^{-3} \mathrm{~mol}\left(R_{\mathrm{co}}=4.94 \times 10^{-2}\right), \quad \mathrm{Ni}$ $\left(\mathrm{NO}_{3}\right)_{2} \cdot 6 \mathrm{H}_{2} \mathrm{O} 1.75 \times 10^{-3} \mathrm{~mol}\left(R_{\mathrm{Ni}}=1.40 \times 10^{-2}\right)$ あるい は $\mathrm{CuCl}_{2} \cdot 2 \mathrm{H}_{2} \mathrm{O} 3.73 \times 10^{-3} \mathrm{~mol}\left(R_{\mathrm{cu}}=3.74 \times 10^{-2}\right)$ をそ れぞれ単独で添加して作製したゲルを，種々の温度で 30 分間熱処理を施して得た試料の X 線回折の結果を図 2 に示す.いずれの試料の場合にも，ムライトの回折線 (○印) のほかに，Al-Si スピネルの回折線 (ム印) が 認められた。 また，鉱化剤を含むいずれの試料の場合に も，ムライトの最強線 $\left(2 \theta=26.3^{\circ}(d=3.39 \AA)\right)$ の相 対強度は，試料 No.1（鉱化剤を含まない）の場合より も顕著であった。さらに $\mathrm{MnCl}_{2}(\mathrm{Mn}-3), \mathrm{CoCl}_{2}(\mathrm{Co}-4)$ および $\mathrm{CuCl}_{2}(\mathrm{Cu}-2)$ などは, $\mathrm{Fe}\left(\mathrm{NO}_{3}\right)_{3}(\mathrm{Fe}-1)$ および $\mathrm{Ni}\left(\mathrm{NO}_{3}\right)_{2}(\mathrm{Ni}-1)$ などよりも低温でムライトの生成を促

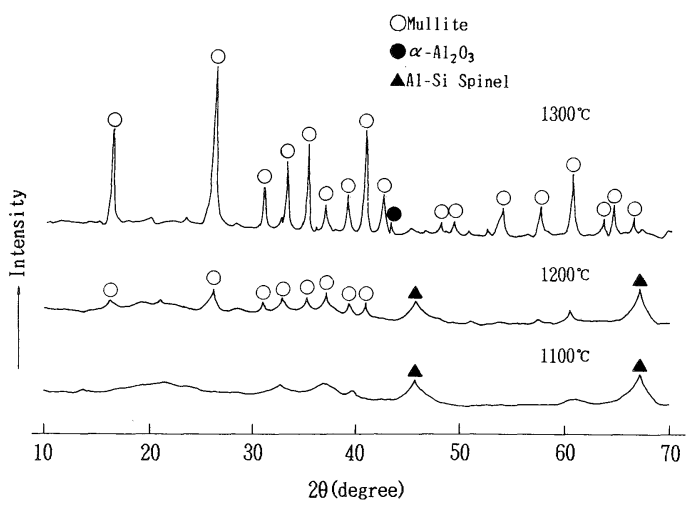

Fig.1. X-ray diffraction patterns of samples (No.1) obtained by heating for $30 \mathrm{~min}$ the gel prepared by hydrolyzing the mixture of $\mathrm{Si}\left(\mathrm{OC}_{2} \mathrm{H}_{5}\right)_{4}$ and $\mathrm{Al}\left(\mathrm{NO}_{3}\right)_{3}$ solution at various temperatures.
OMullite

$\Delta$ Al-Si Spinel

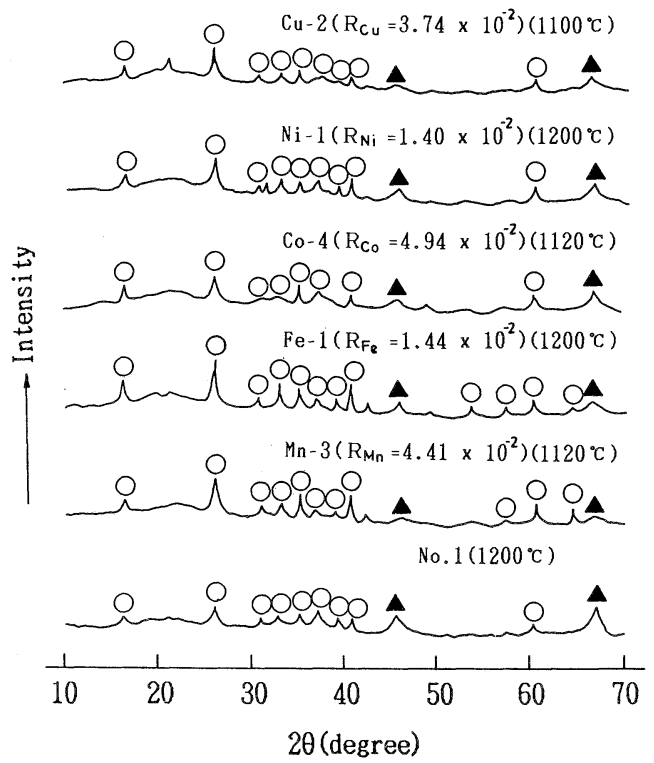

Fig. 2. X-ray diffraction patterns of samples obtained by heating for $30 \mathrm{~min}$ the gels with the small amounts of $\mathrm{MnCl}_{2}, \mathrm{Fe}\left(\mathrm{NO}_{3}\right)_{3}, \mathrm{CoCl}_{2}, \mathrm{Ni}\left(\mathrm{NO}_{3}\right)_{2}$ or $\mathrm{CuCl}_{2}$ at various temperatures.

進する効果が認められた。とくに $\mathrm{CuCl}_{2}(\mathrm{Cu}-2)$ は, 最 も低温 $\left(1100^{\circ} \mathrm{C}\right)$ でムライトの生成に対して促進効果 があった。

$\mathrm{MnCl}_{2} \cdot 4 \mathrm{H}_{2} \mathrm{O} 1.82 \times 10^{-3} \mathrm{~mol}\left(R_{\mathrm{Mn}}=1.47 \times 10^{-2}\right), \mathrm{Fe}$ $\left(\mathrm{NO}_{3}\right)_{3} \cdot 9 \mathrm{H}_{2} \mathrm{O} 8.06 \times 10^{-3} \mathrm{~mol}\left(R_{\mathrm{Fe}}=7.08 \times 10^{-2}\right)$, $\mathrm{CoCl}_{2} \cdot 6 \mathrm{H}_{2} \mathrm{O} 5.43 \times 10^{-3} \mathrm{~mol}\left(R_{\mathrm{Co}}=3.71 \times 10^{-2}\right), \quad \mathrm{Ni}$ $\left(\mathrm{NO}_{3}\right)_{2} \cdot 6 \mathrm{H}_{2} \mathrm{O} 7.01 \times 10^{-3} \mathrm{~mol}\left(R_{\mathrm{Ni}}=5.60 \times 10^{-2}\right)$ あるい は $\mathrm{CuCl}_{2} \cdot 2 \mathrm{H}_{2} \mathrm{O} 1.87 \times 10^{-3} \mathrm{~mol}\left(R_{\mathrm{cu}}=1.88 \times 10^{-2}\right)$ をそ

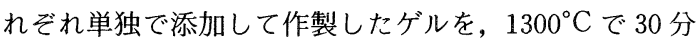
間熱処理を施して得た試料の X 線回折の結果を図 3 に 示す。試料 No.1（鉱化剤を含まない）の場合には，す でに述べたように，ムライトの回折線のほかに， $\alpha$ $\mathrm{Al}_{2} \mathrm{O}_{3}$ の回折線 (○印) が認められたのに対して, 鉱化 䬉を含むいずれの試料の場合には, $\alpha-\mathrm{Al}_{2} \mathrm{O}_{3}$ の回折線 印) は認められなかった。また，ムライトの最強線 $(2 \theta$ $\left.=26.3^{\circ}\right)$ の相対強度は, 試料 No. 1 の場合よりも顕著 であった。したがって, $\mathrm{MnCl}_{2}, \mathrm{Fe}\left(\mathrm{NO}_{3}\right)_{3}, \mathrm{CoCl}_{2}$, $\mathrm{Ni}\left(\mathrm{NO}_{3}\right)_{2}$ および $\mathrm{CuCl}_{2}$ などの鉱化剤は, $1300^{\circ} \mathrm{C}$ にお いてムライトの生成を促進する効果があるものと考えら れる．鉱化㓮のムライトの生成を促進する効果は，鉱化 剤を含む試料のムライトの最強線 $\left(2 \theta=26.3^{\circ}\right)$ の相対 強度を, 試料 No.1 のムライトの最強線の相対強度 (X 線回折図 $(1000 \mathrm{cps})$ におけるムライトの最強線の高さ $(7.80 \mathrm{~cm}))$ と比較した場合, それぞれ約 1.22 倍 $(\mathrm{Ni}-4)$, 1.12 倍 $(\mathrm{Fe}-5), 1.11$ 倍 $(\mathrm{Cu}-1), 1.07$ 倍（Co-3）お 


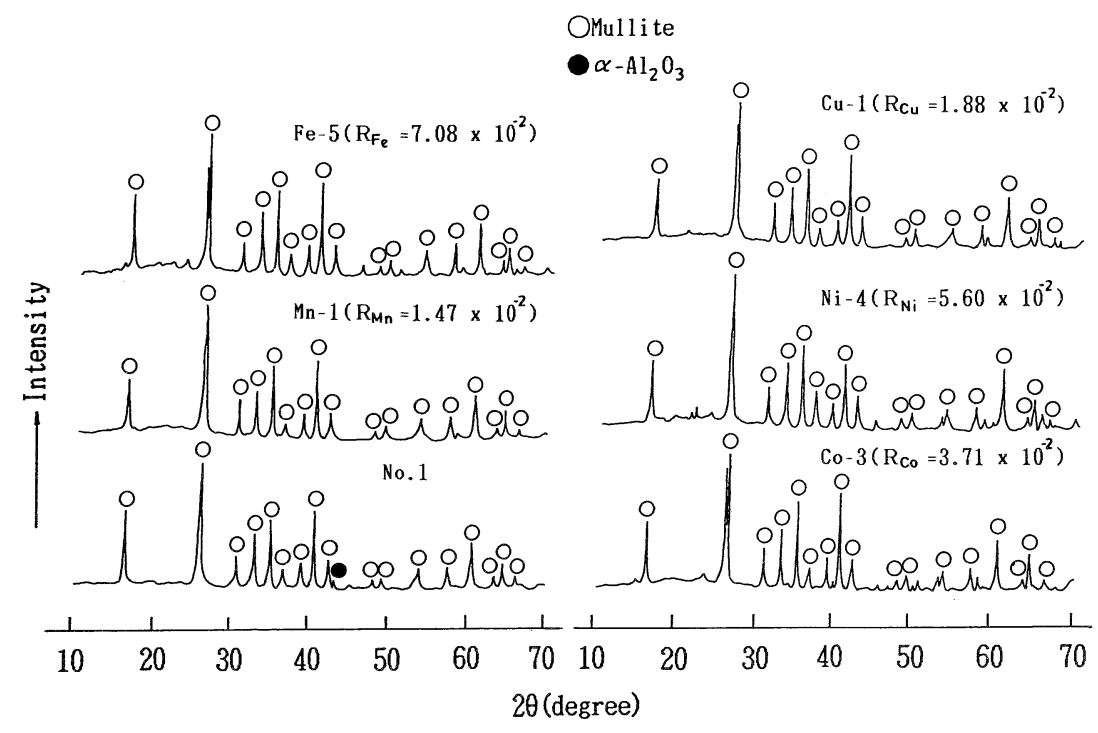

Fig. 3. X-ray diffraction patterns of samples obtained by heating for $30 \mathrm{~min}$ the gels with the small amounts of $\mathrm{MnCl}_{2}, \mathrm{Fe}\left(\mathrm{NO}_{3}\right)_{3}, \mathrm{CoCl}_{2}, \mathrm{Ni}\left(\mathrm{NO}_{3}\right)_{2}$ or $\mathrm{CuCl}_{2}$ at $1300^{\circ} \mathrm{C}$.

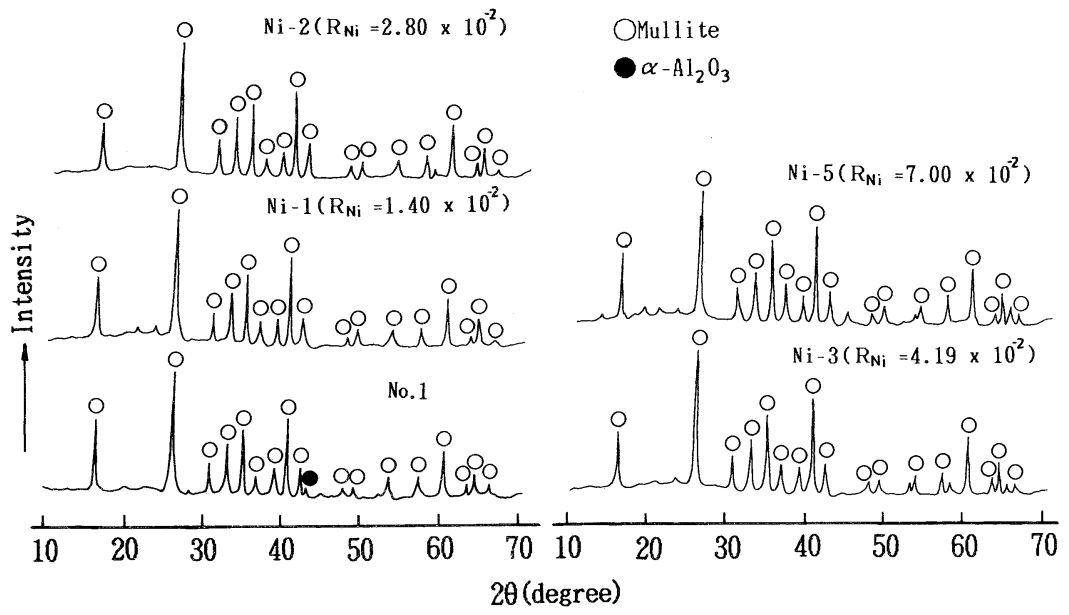

Fig. 4. X-ray diffraction patterns of samples obtained by heating for $30 \mathrm{~min}$ the gels with various amounts of $\mathrm{Ni}\left(\mathrm{NO}_{3}\right)_{2}$ at $1300^{\circ} \mathrm{C}$.

よび 1.06 倍 $(\mathrm{Mn}-1)$ となり, $\mathrm{Ni}\left(\mathrm{NO}_{3}\right)_{2}>\mathrm{Fe}\left(\mathrm{NO}_{3}\right)_{3}>$ $\mathrm{CuCl}_{2}>\mathrm{CoCl}_{2}>\mathrm{MnCl}_{2}$ の順であった。このように, $\mathrm{Ni}$ $\left(\mathrm{NO}_{3}\right)_{2}$ がムライトの生成に対して最も促進効果があっ た.

$\mathrm{Ni}\left(\mathrm{NO}_{3}\right)_{2} \cdot 6 \mathrm{H}_{2} \mathrm{O} 1.75 \times 10^{-3} \mathrm{~mol}(\mathrm{Ni}-1), 3.50 \times 10^{-3}$ mol (Ni-2), $5.25 \times 10^{-3} \mathrm{~mol}(\mathrm{Ni}-3)$ および $8.76 \times 10^{-3}$ mol（Ni-5）をそれぞれ単独で添加して作製したゲルを, $1300^{\circ} \mathrm{C}$ で 30 分間熱処理を施して得た試料の $\mathrm{X}$ 線回折 の結果を図 4 に示す、Ni-1，Ni-2，Ni-3 および Ni-5 の いずれの試料の場合にも, ムライトの最強線 $(2 \theta=$ $\left.26.3^{\circ}\right)$ の相対強度は, 試料 No. 1 の場合よりも約 1.08
倍（Ni-1），1.07倍（Ni-2），1.14 倍（Ni-3）および 1.07 倍（Ni-5）大きいので, いずれの添加量において もムライトの生成を促進する効果が認められた。した がって, $\mathrm{Ni}\left(\mathrm{NO}_{3}\right)_{2}$ は, 本研究で用いた添加量の範囲内 では, いずれの添加量の場合にもムライトの生成を促進 し，ムライトの合成に対する鉱化剤として有効であると 考えられる.

最後に，本報のゾルゲル法によって得たムライトの合 成結果は,これまで, 種々の方法によって得られている ムライトの合成結果 ${ }^{7), 9)}$ と比較しても遜色のないもので あった。 


\section{文 献}

1) N. L. Bowen and J. W. Greig, J. Am. Ceram. Soc., 7, 238-54 (1924).

2) P.C. Dokko, J.A. Pask and K.S. Mazdiyasni, J. Am. Ceram.Soc., 60, 150-55 (1977).

3）神崎修三, 熊沢 猛, 浅海順治, 阿部修実, 田端英世, 窯協, 93, 407-08 (1985).

4）熊沢 猛, 神崎修三, 浅海順治, 阿部修実, 田端英世, 窂協, 94, 485-90 (1986).

5）桜井 修, 水谷惟恭, 加藤誠軌, セラミックス論文誌, 96 , 639-45 (1988).

6）平田好洋, 酒田一義, 松下由美, 島田欣二, 篝協, 93, 577-80 (1985).
7）鈴木久男, 友清芳二, 陶山容子, 斉藤 肇, セラミック ス論文誌, 96, 67-73 (1988).

8）平田好洋, 南園広志, 島田欣二, 窯協, 93，36-44 (1985)

9）鈴木松郎, 平石俊一, 吉村昌弘, 宗宮重行, 窯協, 92, 320-27 (1984).

10）山口敏秀, 鈴木松郎, 平石俊一, 吕村昌弘, 宗宮重行, 窯協, 93，101-04 (1985).

11）門側幸宏，山手 有，窯協，93，338-40（1985）。

12）門側幸宏, 山手 有, 電気化学, 53, 831-33 (1985).

13）門側幸宏, 川上隆通, Chemistry Express, 3, 239-42 (1988)。

14）斉藤 肇, 潮 真澄, 窯協, 76, 337-50 (1968).

15）田賀井秀夫, “無機材料数値表”化学工業社（1969） pp. 209-10. 